\title{
Evaluation of the Effects of Novel Nafimidone Derivatives on Thermal Hypoalgesia in Mice with Diabetic Neuropathy
}

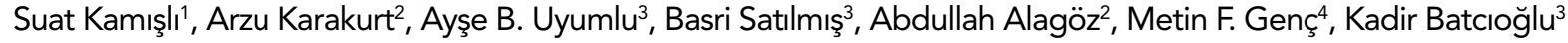 \\ ${ }^{1}$ Department of Neurology, Faculty of Medicine, Inönü University, Malatya, Turkey \\ ${ }^{2}$ Department of Pharmaceutical Chemistry, Faculty of Pharmacy, Inönü University, Malatya, Turkey \\ ${ }^{3}$ Department of Biochemistry, Faculty of Pharmacy, Inönü University, Malatya, Turkey \\ ${ }^{4}$ Department of Public Health, Faculty of Medicine, Inönü University, Malatya, Turkey
}

\section{ABSTRACT}

Objective: Diabetic neuropathy (DN) is a common complication in Diabetes Mellitus. The streptozotocin-induced diabetic rodent is the most commonly used animal model of diabetes and increased sodium channel expression and activity were revealed in this model. At this study, we evaluated the effect of three different nafimidone derivatives which have possible anticonvulsant activity on disorders of thermal pain sensation in diabetic mice.

Study Design: Randomized animal experiment.

Material and Methods: Mice were divided randomly into five groups (5 mice per group): Control, Diabetes, Dibetes+C1, Diabetes+C2, Diabetes+C3. We used hot and cold plate, and tail-immersion tests for assessment of thermal nociceptive responses.

Results: Compared with the control group, the hot-plate response time and the number of paw liftings on cold plate as important indicators of loss of sensation increased, but no significant difference $(p>0.05)$ was found in tail-immersion response time test in diabetes group. C3 compound moved it back to control group levels in the all of three tests. C1 and C2 compounds were effective only in cold-plate test.

Conclusion: Nafimidone derivatives may be effective in the cases where epilepsy and diabetes occur together since it has shown efficacy against "loss of sensation" which evolves in diabetic neuropathy over time as well as its antiepileptic effect.

Key Words: Diabet, diabetic neuropathy, loss of sensation, antiepileptic, Na channel blocker, nafimidone derivatives

Received: 14.04.2012 Accepted: 07.07.2012

\section{Introduction}

The worldwide diabetes epidemic has shown no signs of abatement. Its prevalence has more than doubled since 1980 (1). Diabetic neuropathy (DN) is the most common diabetic complication, afflicting over $50 \%$ of all diabetics. The possible biochemical pathomechanisms include oxidative stress, activation of the polyol pathway, increased advanced glycation end products (AGEs) and their receptors, impaired ionic homeostasis of cells and activation of protein kinases (PKC and PKA), and mitogen-activated protein kinases (MAPK), and inducible nitric oxide synthase (2-6).

Understanding the biochemical mechanisms underlying diabetic neuropathic pain and sensory disorders requires preclinical studies in animal models. The streptozotocin (STZ)induced diabetic rodent is the most commonly used animal model of diabetes $(7,8)$. On the other hand, existing animal models of diabetic painful and insensate neuropathy, however, have serious limitations. Diabetic rats and mice have limited life span and rarely show evidence of overt neuropathy, such as demyelination, axonal degeneration, fiber loss, or axonal regeneration in their peripheral nerves. This makes diabetic rodents unsuitable for studying the contribution of these phenomena of DN to pain or to loss of sensory function (9). Nonetheless, despite these limitations, assessment of behavioral responses to external stimuli in diabetic rats and mice (i.e., thermal and mechanical hyper and hypoalgesia, tactile allodynia, as well as formalin-induced spontaneous nociceptive behavior) has led to identification of a number of mechanisms of loss of sensation and/or pain in diabetes (10).

Decades of research elucidating the pathophysiology of diabetic neuropathy have failed, thus far, to produce a treatment that prevents or reverses its development and progression. Recently, however, numerous competing or parallel pathological pathways have begun to intersect and complement each other, illuminating potential pharmacologic targets. The current foci of diabetic neuropathy research are excessive activation of sodium channels and corrupted molecular mechanisms of cellular pathways of related kinases (11).

Voltage-gated sodium channels ( $\mathrm{Na}_{\mathrm{v}} \mathrm{Chs}$ ) are a necessary component of normal sensation, emotions, thoughts and movements and are of particular interest as target for neuro- 
pathic disorders because they control electrical signals in both the central and peripheral nervous systems $(12,13)$. Recently, blocking of this channel has been widely accepted as a potential treatment for diabetic pain and insensate neuropathy (14). At this point, the possibility of selectively modulating sodium channels involved in neuropathic disorders has been based on the following three strategies: i) development of non-selective sodium channel blockers that are potent and highly usedependent; ii) discovery of molecules with peripheral activity, thereby, avoiding CNS side effects and iii) identification of selective sodium channel blockers that specifically target channel subtypes associated with diabetic complications. In this respect, $\mathrm{Na}_{\mathrm{v}}$ Chs can be considered as 'selective targets' (15).

During anticonvulsant drug development studies, the activity of the compounds usually first tested in the conventional acute animal models but recently investigation of the activity of the promising compounds for the other pathophysiological issues such as neuropathic disorders has become rutin (NINDS, ASP). Nafimidone is an example of (arylalkyl) azoles, which possess a profile of activity similar to that of phenytoin or carbamazepine but distinct from barbiturates or valproic acid. Nafimidone alcohol, the major metabolite of nafimidone, also has high anticonvulsant activity. SAR studies of (arylalkyl) azole anticonvulsant compounds have shown that the anticonvulsant properties of this group are associated with the presence of a small oxygen functional group (such as carbonyl, ethylene dioxy, methoxy, acyloxy, hydroxyl and oxime ether substituents) in the alkylene bridge in addition to imidazole ring and lipophilic aryl portion facilitating penetration through blood-brain barrier (16).

In this study, in the light of available literature and as a continuation of our previous studies on anticonvulsant nafimidone derivatives, we aimed to evaluate the effects of some new oxime ester derivatives of nafimidone on disorders of thermal pain sensation in diabetic mice (17-19).

\section{Material and Methods}

\section{Animals}

A total of 25 female BALB/c albino mice (five months old) were used. The colony was obtained from the Laboratory Animals Research Center of Inonu University, Malatya, Turkey; all handling and maintenance conditions were according to the rules and regulations of the local Institutional Ethic Committee. The animals weighing $28-30 \mathrm{~g}$ were housed in a room maintained at $22^{\circ} \mathrm{C}$ with a $12: 12 \mathrm{~h}$ light-dark cycle, and had free access to food. Mice were divided randomly into five groups (5 mice per group): Group I served as "control" and mice were untreated. Mice in Group II, III, IV and V were injected intraperitonally each with a single dose of $150 \mathrm{mg} / \mathrm{kg}$ body weight of streptozotocin (Sigma Chemicals), dissolved in $0.9 \% \mathrm{NaCl}$ solution and given in a volume of $0.5 \mathrm{~mL}(20)$. Mice in control group received an equivalent volume of $0.9 \%$ $\mathrm{NaCl}$ solution. The diabetes was confirmed one week after the streptozotocin injection by measuring the blood glucose level with a portable analyzer (Lever Check, Muenster, Germany) using glucose oxidase peroxidase enzyme reagent stripes. Blood was withdrawn from the tail ven of mice with a heparin- ized capillary tube. Animals with a non-fasting serum glucose levels above $275 \mathrm{mg} / \mathrm{dL}$ were considered diabetic and used for the all tests after five weeks.

\section{Compounds and administration}

New compounds 2-(1H-imidazol-1-yl)-1-(naphthalene-2-yl) ethanone O-pentanoyl oxime hydrochloride (C1), 2-(1 H-imidazol-1-yl)-1-(naphthalene-2-yl)ethanone O-3-methylbutanoyl oxime hydrochloride (C2), 2-(1H-imidazol-1-yl)-1-(naphthalene2-yl)ethanone O-2-propylpentanoyl oxime hydrochloride) (C3) were prepared by esterification of the nafimidone oxime with carboxylic acid and dicyclohexilcarbodiimide/4-dimethylaminopyridine (DCC/DMAP). All compounds were synthesized at Inonu University, Faculty of Pharmacy, Department of Pharmaceutical Chemistry. The structures of the all compounds were confirmed by IR, ${ }^{1} \mathrm{H}-\mathrm{NMR}$, Mass spectral and elementary analysis (19). Thirty minutes before starting the tests, $100 \mathrm{mg} / \mathrm{kg} \mathrm{b.w.}$ dose - C1 to the first group of the mice; $100 \mathrm{mg} / \mathrm{kg} \mathrm{b.w.} \mathrm{dose-}$ $\mathrm{C} 2$ to the second group of the mice; and $100 \mathrm{mg} / \mathrm{kg}$ b.w. doseC3 to the third group of the mice were injected i.p. We tested antiepileptic activity of all new compounds via MES test and found $100 \mathrm{mg} / \mathrm{kg}$ b.w. as the most effective dose before main experimental process. All three compounds were suspended in $30 \%$ PEG-400 (Polyethylene glycol). To the control group only $30 \%$ PEG-400 which is used as solvent was injected i.p.

\section{Assessment of thermal nociceptive responses}

Thermal nociceptive responses were assessed by hot and cold plate, and tail-immersion test methods. Animals were always habituated to the testing environment more than $60 \mathrm{~min}$ prior to the test. Each mouse was tested only once at $30 \mathrm{~min}$ post-injection. The observer did not know which agent was being tested.

\section{Hot plate test}

The hot plate test was used to measure latency by the method of Bispo et al. (21) with small modifications. The temperature of the plate (Model MK-350B, Muromachi Kikai Co., Japan) was fixed at $53 \pm 0.2^{\circ} \mathrm{C}$. A cut off time of $15 \mathrm{sec}$ was maintained at $53^{\circ} \mathrm{C}$ to prevent tissue damage. The reaction time (jumping, licking one of the hind legs or one of the forelegs, tapping) was measured $30 \mathrm{~min}$ after intraperitoneal (i.p.) administration of the drug solution.

\section{Tail-immersion test}

The distal part of the tails of the animals was immersed in hot water maintained at $55.0 \pm 1.0^{\circ} \mathrm{C}$. The time taken to withdraw the tail was noted as reaction time (22). Prior to the experiment the mice were screened for the sensitivity test by immersing the tail of the mice gently in hot water maintained at $55^{\circ} \mathrm{C}(23)$. A cut off time of $10 \mathrm{sec}$ was maintained at $55^{\circ} \mathrm{C}$ to prevent tissue damage. This test was carried out at $30 \mathrm{~min}$ after i.p. administration of the compounds.

\section{Cold-plate test}

Mice were placed on a cold metal plate maintained at $4 \pm 1^{\circ} \mathrm{C}$ and covered with a transparent plastic box $(24 \times 24 \times 21$ $\mathrm{cm})$. Brisk lifting of the left hind paw was counted as a noci- 
ceptive response, and the number of such responses over a 2 min period was recorded and scored by an observer who was blind to the treatment condition. Walking steps and slow paw lifting related to locomotion were not counted (24).

\section{Statistical analysis}

Analysis of Variance, (ANOVA) was performed to all the data and these were followed by a post hoc LSD test for differences between paired groups. It was observed that all the data conformed to normal distribution except blood glucose level. Therefore, nonparametric Kruskal Wallis of variance and Mann-Whitney $U$ tests were performed for the values of glucose. The statistical significance level was set at $p<0.05$.

\section{Results}

Within 3 days of the STZ injection developed hyperglycemia in mice. Diabetic mice showed polyuria, a marked increase in food and water intake, and failed to gain weight (Table 1).

Approximately $20 \%$ loss in body weight was determined in STZ injected grups. However, mice showed marked hypoalgesia after 6 weeks of diabetes. According to our findings; compared with the control group, the hot-plate response time and the number of paw liftings on cold plate as important indicators of loss of sensation increased, but no significant difference $(p>0.05)$ was found in tail-immersion response time test in diabetes group. However, used novel therapeutic compounds affected in varying degrees of these responses. Especially, C3 compound was the most effective agent in the all of three tests. C1 and C2 compounds were effective only in cold-plate test.

\section{Discussion}

Type I and II diabetic patients are affected by diabetic neuropathy that usually develops as an initial phase of hyperalgesia and allodynia followed by a later phase of hypoalgesia. Associated with DN, assessment of altered responses to both nociceptive and non-nociceptive stimuli in diabetic rats and mice is performed using a number of behavioural tests, among which paw withdrawal, tail flick, hot-plate and cold-plate are the most widely used. In general, tail-immersion test at spinal level; hot-plate test at both spinal and supraspinal level and cold-plate test through peripheral sensitization give an idea to evaluate the pain perception and transmission $(25,26)$.

There is a general agreement that diabetic neuropathy in animal models is characterized by a disruption in peripheral nerve function $(27,28)$. All previous studies describe decreased nerve conduction velocity in diabetic animals, although the magnitude varies $(29,30)$. Also altered thermal perception has been described and is manifested by thermal hyperalgesia or hypoalgesia $(31,32)$. We can say that our findings agree with mentioned previous works; we observed thermal hypoalgesia in mice 6 weeks after the STZ injection.

Four main hypotheses about how hyperglycaemia and/or low insulin levels causes diabetic complications are: increased polyol pathway flux, increased advanced glycation end-products (AGEs) formation, activation of protein kinases (PKC and PKA), and increased hexosamine pathway flux (33). Additionally, it has been suggested that, as a result of deteriorated sodium channel activation due to continued hyperglycemia, increased flow of sodium into the cell, in connection with the above mentioned mechanisms, plays an important role in the pathogenesis (34).

$\mathrm{Na}_{\mathrm{v}} \mathrm{Chs}$ in the cell membrane of the nociceptor neurons are integral heteromeric protein complexes that selectively conduct $\mathrm{Na}^{+}$ions and amplify membrane depolarisation, thus resulting in the generation and propagation of action potentials that pass into the dorsal horn of the spinal cord (35). It has now been established from electrophysiological and molecular biological techniques that $\mathrm{Na}_{v}$ Chs play an important role in the molecular pathophysiology of DN (36). As it is known, high glucose stimulates increased kinases' activity through increased cAMP, which can increase $\mathrm{Na}_{\mathrm{v}} \mathrm{Ch}$ trafficking and thus potentiate the sodium current (37).

The underlying molecular mechanisms of hyper and hypoalgesia observed in different stages of diabetic neuropathy

Table 1. The animals were weighed at the beginning and end of the experiment. Statistically significant difference between control and other three groups were displayed. Also, blood glucose levels ( $\mathrm{mg} / \mathrm{dL}$ ) and results of tail-immersion (latency time as seconds), hot-plate (latency time as seconds) and cold-plate (number of brisk lifting of the left hind paw) tests were summarized. Results were expressed as Mean+SE

\begin{tabular}{|c|c|c|c|c|c|c|}
\hline \multirow{2}{*}{$\begin{array}{l}\text { Groups } \\
(n=5)\end{array}$} & \multirow{2}{*}{$\begin{array}{l}\text { Blood Glucose } \\
\text { (mg/dL) }\end{array}$} & \multirow{2}{*}{$\begin{array}{l}\text { Tail-immersion } \\
\text { response time } \\
\text { (sec) }\end{array}$} & \multirow{2}{*}{$\begin{array}{l}\text { Hot-plate } \\
\text { response time } \\
\text { (sec) }\end{array}$} & \multirow{2}{*}{$\begin{array}{l}\text { Cold-plate } \\
\text { (the number } \\
\text { of paw liftings) }\end{array}$} & \multicolumn{2}{|c|}{ Body Weight (g) } \\
\hline & & & & & $\begin{array}{l}\text { Before STZ } \\
\text { injection }\end{array}$ & $\begin{array}{l}6 \text { weeks after } \\
\text { STZ injection }\end{array}$ \\
\hline Control & $127.2 \pm 4.09^{b, c, d, e}$ & $5.4 \pm 0.94$ & $7.0 \pm 0.36^{\mathrm{b}, \mathrm{d}, \mathrm{e}}$ & $6.3 \pm 0.79^{b}$ & $30.6 \pm 2.1$ & $31.3 \pm 1.8^{b, c, d, e}$ \\
\hline Diabetes & $293.6 \pm 8.68^{a}$ & $7.5 \pm 1.81$ & $11.5 \pm 2.01^{\mathrm{a}, \mathrm{e}}$ & $2.5 \pm 0.31^{a, c, d}$ & $29.4 \pm 1.9$ & $23.7 \pm 1.5^{\mathrm{a}}$ \\
\hline Diabetes+C1 & $277.0 \pm 7.76^{a}$ & $5.3 \pm 0.56$ & $10.9 \pm 2.20^{e}$ & $6.7 \pm 0.86^{b}$ & $30.2 \pm 2.3$ & $24.9 \pm 2.0^{\mathrm{a}}$ \\
\hline Diabetes+C2 & $286.4 \pm 6.82^{\mathrm{a}}$ & $6.4 \pm 1.24$ & $13.7 \pm 1.73^{\mathrm{a}, \mathrm{e}}$ & $5.42 \pm 0.73^{b}$ & $31.1 \pm 1.7$ & $25.2 \pm 2.2^{\mathrm{a}}$ \\
\hline Diabetes+C3 & $283.6 \pm 9.34^{a}$ & $3.9 \pm 0.63^{b}$ & $4.43 \pm 0.25^{a, b, c, d}$ & $6.92 \pm 1.08^{b}$ & $29.7 \pm 1.8$ & $24.5 \pm 2.1^{\mathrm{a}}$ \\
\hline \multicolumn{7}{|c|}{$\begin{array}{l}{ }^{a} p<0.05 \text { when compared with Control group } \\
b p<0.05 \text { when compared with Diabetes group } \\
{ }^{c} p<0.05 \text { when compared with Diabetes }+C 1 \text { group } \\
{ }^{d} p<0.05 \text { when compared with Diabetes }+C 2 \text { group } \\
\text { ep } p<0.05 \text { when compared with Diabetes + C3 group } \\
\text { STZ: Streptozotocin }\end{array}$} \\
\hline
\end{tabular}


is very complex. It has been suggested that hyperactivity of small, unmyelinated C-fibers results in hyperalgesia and allodynia (36). Also, Khan et al. (38) reported that A-fiber afferents in diabetic rats developed abnormal spontaneous discharges and increased sensitivity to mechanical stimuli, suggesting a role of large A-fiber neurons in addition to nociceptive $\mathrm{C}$-fibers in the development of diabetic neuropathic pain in early stage of DM.

In our opinion, according to results of previous studies in the literature, a few weeks after induction of hyperglycemia, there is an increased expression and/or activation of $\mathrm{Na}_{\mathrm{v}} \mathrm{Chs}$ that play an important role on developing of hyperexcitability in early stage of $\mathrm{DM}$, but the possible role of $\mathrm{Na}_{\mathrm{v}} \mathrm{Chs}$ on occured hypoexcitability and hyposensation as major symptoms of the later stage of DM 6-8 weeks after induction of hyperglycemia is still unknown. As one of the possible reasons, increase intracellular sodium was attributed to a decrease in the activity of $\mathrm{Na}^{+} / \mathrm{H}^{+}$exchange system and may be due to low intracellular $\mathrm{pH}$. Increased acidity may suppress excitability and/or conduction (33). Oskarsson et al. (39) reported that mexiletine, a sodium channel blocker, has proven to be a very safe therapy with negligible side effects in DN. However, all the molecular mechanisms involved in the formation of "loss of sensation" developing over time and hypoalgesia as a result of that loss have not yet been fully clarified.

In the literature, neurodegenerative damage caused by hyperglycemia and oxidative stress, usually due to long term hyperglycemia, is emphasized to characterize by message function disorders occuring along the myelinated and unmyelinated nerves (40). In addition, it is suggested that an increased ion influx to the cell from over-activated sodium and calcium channels due to phosphorylation caused by PKC and PKA activations plays a role in the pathogenesis (33). With a hypothetical approach; a long-term hyper excitability may have caused neural insensitivity in time. Our research findings indicate that increased sodium channel expression and activation in untreated diabetes play a role in formation mechanism of hypoalgesia in time and sodium channel blockage significantly prevents loss of sensation caused by intra cellular excessive sodium presence by obstructing the flow of sodium into the cell.

Valproic acid derivatives among nafimidone oxime esters that we have used in the research; 2-(1H-imidazol-1-yl)1-(naphthalene-2-yl)ethanone 0 -2-propylpentanoyl oxime hydrochloride (C3), were effective in all three thermal response tests and significantly inhibited the loss of sensation which evolves due to diabetes in time. The other two derivative compounds 2-(1H-imidazol-1-yl)-1-(naphthalene-2-yl) ethanone O-pentanoyl oxime hydrochloride (C1) and 2- $(1 \mathrm{H}$-imidazol1-yl)-1-(naphthalene-2-yl) ethanone O-3-methylbutanoyl oxime hydrochloride (C2) were only effective at cold-plate test whereas it indicated no activity at tail-immersion and hot-plate tests.

In this context, it can be stated that the $\mathrm{C} 3$ derivative molecule is effective on pain transmission ways through both spinal and supraspinal and peripheral sensitization and the other two derivative molecules $\mathrm{C} 1$ and $\mathrm{C} 2$ were only effective on pain transmission way through peripheral sensitization. Although all these three derivatives are among nafimidone oxime esters, probable reason of why only $\mathrm{C} 3$ is more effective may be the lipophilic character it gained due to valporic acid in comparison with others. On the other hand, $\mathrm{Na}_{v}$ Chs are multimeric structures composed of many subunits. Increases in the expression and activity of the different subunits can be observed in different pathologies. Each of the derivative structures that we have synthesized, are likely to cause blockage at different levels by acting on different subunits.

As a result, it can be suggested that valproic acid derivative of nafimidone oxime may be effective in the cases where epilepsy and diabetes occur together since it has shown efficacy against "loss of sensation" which evolves in diabetic neuropathy over time as well as its antiepileptic effect. However, further molecular studies are needed on animals and humans to determine on which subunits of sodium channels those new derivative compounds are effective or what other mechanisms they are active in and the levels of doses and bioavailability.

Ethics Committee Approval: Ethics committee approval was received for this study.

\section{Informed Consent: N/A.}

Peer-review: Externally peer-reviewed.

Author contributions: Concept - S.K.; Design - S.K., A.K.; Supervision - S.K., A.K., K.B.; Resource - A.K.; Materials - A.A.; Data Collection\&/or Processing - M.G., B.S., B.U.; Analysis\&/or Interpretation K.B., B.S., B.U.; Literature Search - B.S., B.U., A.A.; Writing - S.K., A.K., K.B.; Critical Reviews - M.G.

Conflict of Interest: No conflict of interest was declared by the authors.

Financial Disclosure: This study was supported by Inonu University Research Project Unit (IUBAP) Malatya, Turkey (Project Number: 2011/66).

\section{References}

1. Danaei G, Finucane MM, Lu Y, Singh GM, Cowan MJ, Paciorek $\mathrm{CJ}$, et al. National, regional, and global trends in fasting plasma glucose and diabetes prevalence since 1980:systematic analysis of health examination surveys and epidemiological studies with 370 country-years and 2.7 million participants. Lancet 2011;378:31-40. [CrossRef]

2. Vincent AM, Russell JW, Low P, Feldman EL. Oxidative stress in the pathogenesis of diabetic neuropathy. Endocr Rev 2004;25:612-28. [CrossRef]

3. Oates PJ. Polyol pathway and diabetic peripheral neuropathy. Int Rev Neurobiol 2002;50:325-92. [CrossRef]

4. Toth C, Rong LL, Yang C, Martinez J, Song F, Ramji N, et al. Receptor for advanced glycation end products (RAGEs) and experimental diabetic neuropathy. Diabetes 2008;57:1002-17. [CrossRef]

5. Tomlinson DR. Mitogen-actiavated protein kinases as glucose transducers for diabetic complications. Diabetologia 1999;42:1271-81. [CrossRef]

6. Chan L, Terashima T, Urabe H, Lin F, Kojima H. Pathogenesis of diabetic neuropathy:bad to the bone. Ann NY Acad Sci 2011;1240:70-6. [CrossRef]

7. Konrad R, Mikolaenko I, Tolar J, Liu K, Kudlow J. The potential mechanism of the diabetogenic action of streptozotocin:Inhibition of pancreatic beta-cell O-GlcNAc-selective N-acetyl-b-D-glucosaminidase. Biochem J 2001;356:31-41. [CrossRef]

8. Elsner M, Guldbakke B, Tiedge M, Munday R, Lenzen S. Relative importance of transport and alkylation for pancreatic b-cell toxicity of streptozotocin. Diabetologia 2000;43:1528-33. [CrossRef] 
9. Otto KJ, Wyse BD, Cabot PJ, Smith MT. Insulin implants prevent the temporal development of mechanical allodynia and opioid hyposensitivity for 24-wks in streptozotocin (stz)-diabetic wistar rats. Pain Med 2011;12:782-93. [CrossRef]

10. Obrosova IG. Diabetic painful and insensate neuropathy:pathogenesis and potential treatments. Neurotherapeutics 2009;6:638-47. [CrossRef]

11. Hong S, Wiley JW. Early painful diabetic neuropathy is associated with differential changes in tetrodotoxin-sensitive and -resistant sodium channels in dorsal root ganglion neurons in the rat. J Bio Chem 2004;279:29341-50.

12. Catterall WA. Structural biology:A 3D view of sodium channels. Nature 2001;409:988-90. [CrossRef]

13. Bhattacharya A, Wickenden AD, Chaplan SR. Sodium channel blockers for the treatment of neuropathic pain. Neurotherapeutics 2009;6:663-78. [CrossRef]

14. Lai J, Hunter JC, Porreca F. The role of voltage-gated sodium channels in neuropathic pain. Curr Opin Neurobiol 2003;13:291-7. [CrossRef]

15. Zuliani V, Rivara M, Fantini M, Costantino G. Sodium channel blockers for neuropathic pain. Expert Opin Ther Pat 2010;20:755-79. [CrossRef]

16. Dalkara S, Karakurt A. Recent progress in anticonvulsant drug research:strategies for anticonvulsant drug development and applications of antiepileptic drugs for non-epileptic central nervous system disorders. Curr Top Med Chem 2012;12:1033-71. [CrossRef]

17. Karakurt A, Özalp M, Işık Ş, Stables JP, Dalkara S. Synthesis, anticonvulsant and antimicrobial activities of some new 2-acetylnaphthalene derivatives. Bioorg Med Chem 2010;18:2902-11. [CrossRef]

18. Karakurt A, Dalkara S, Özalp M, Özbey S, Kendi E, Stables JP. Synthesis of some 1-(2-naphthyl)-2-(imidazole-1-yl)ethanone oxime and oxime ether derivatives and their anticonvulsant and antimicrobial activities. Eur J Med Chem 2001;36:421-33. [CrossRef]

19. Alagöz A. Studies on new (arylalkyl)imidazole compounds, synthesis and anticonvulsant activities. Master Thesis of Inonu University, Health Sciences Institute, Department of Pharmaceutical Chemistry, 2011

20. Dan M, Chantler JK. A novel pancreatropic coxsackievirus vector expressing glucagon-like peptide 1 reduces hyperglycemia in streptozotocin-treated mice. J Virol 2011;85:12759-68. [CrossRef]

21. Bispo MD, Mourao RHV, Franzotti EM, Bomfim KBR, Arrigoni-Blank MF, Moreno MPN, et al. Antinociceptive and antiedematogenic effects of the aqueous extract of Hyptis pectinata leaves in experimental animals. J Ethnopharmacol 2001;76:81-6. [CrossRef]

22. Nainwal P, Kalra K, Nanda D, Singh A. Study of analgesic and anti-inflammatory activities of the ethanolic extract arial parts of Fumaria Vaillantii Loisel. Asian J Pharm Clin Res 2011;4:90-1.

23. Ahmadi A, Khalili M, Mihandoust F, Barghi L. Synthesis and determination of acute and chronic pain activities of 1-(1-(3-methylphenyl)-(tetralyl))piperidine as a new derivative of phencyclidine via tail immersion and formalin tests. Arzneimittelforschung 2010;60:30-5.

24. Berrocoso E, De Benito MD, Mico JA. Role of serotonin 5-HT1A and opioid receptors in the antiallodynic effect of tramadol in the chronic constriction injury model of neuropathic pain in rats. Psychopharmacology (Berl) 2007;193:97-105. [CrossRef]

25. Jasmin L, Kohan L, Franssen M, Janni G, Goff JR. The cold plate as a test of nociceptive behaviors:description and application to the study of chronic neuropathic and inflammatory pain models. Pain 1998;75:367-82. [CrossRef]

26. Haranishi Y, Hara K, Terada T, Nakamura S, Sata T. The antinociceptive effect of intrathecal administration of glycine transporter-2 inhibitor ALX1393 in a rat acute pain model. Anesth Analg 2010;110:615-21. [CrossRef]

27. Yasuda H, Terada M, Maeda K, Kogawa S, Sanada M, Haneda M, et al. Diabetic neuropathy and nerve regeneration. Prog Neurobiol 2003;69:229-85. [CrossRef]

28. Kamiya $H$, Zhang W, Sima AA. Degeneration of the Golgi and neuronal loss in dorsal root ganglia in diabetic BioBreeding/ Worcester rats. Diabetologia 2006:49:2763-74. [CrossRef]

29. Biessels GJ, Kamal A, Ramakers GM, Urban IJ, Spruijt BM, Erkelens DW, et al. Place learning and hippocampal synaptic plasticity in streptozotocin-induced diabetic rats. Diabetes 1996;45:1259-66. [CrossRef]

30. Andriambeloson E, Baillet C, Vitte PA, Garotta G, Dreano M, Callizot N. Interleukin- 6 attenuates the development of experimental diabetes-related neuropathy. Neuropathology 2006;26:32-42. [CrossRef]

31. Drel VR, Mashtalir N, Inytska O, Shin J, Li F, Lyzogubov VV, et al. The leptin-deficient (ob/ob) mouse:a new animal model of peripheral neuropathy of type 2 diabetes and obesity. Diabetes 2006;55:3335-43. [CrossRef]

32. Obrosova IG, Ilnytska O, Lyzogubov VV, Pavlov IA, Mashtalir N, Nadler JL, et al. High-fat diet induced neuropathy of pre-diabetes and obesity:effects of "healthy" diet and aldose reductase inhibition. Diabetes 2007;56:2598-608. [CrossRef]

33. Brownlee M. Biochemistry and molecular cell biology of diabetic complications. Nature 2001;414:813-820. [CrossRef]

34. Misawa S, Sakurai K, Shibuya K, Isose S, Kanai K, Ogino J, et al. Neuropathic pain is associated with increased nodal persistent $\mathrm{Na}(+)$ currents in human diabetic neuropathy. J Peripher Nerv Syst 2009;14:279-84. [CrossRef]

35. Aldrich RW, Corey DP, Stevens CF. A reinterpretation of mammalian sodium channel gating based on single channel recording. Nature 1983;306:436-41. [CrossRef]

36. Gold MS. Na+ channel blockers for the treatment of pain:context is everything, almost. Exp Neurol 2008;210:1-6. [CrossRef]

37. Weston RM, Subasinghe KR, StaikopoulosV, Jarrott B. Design and assessment of a potent sodium channel blocking derivative of mexiletine for minimizing experimental neuropathic pain in several rat models. Neurochem Res 2009:34:1816-23. [CrossRef]

38. Khan S, Zhou L. Characterization of non-length-dependent smallfiber sensory neuropathy. Muscle Nerve 2012;45:86-91. [CrossRef]

39. Oskarsson P, Ljunggren JG, Lins PE. Efficacy and safety of mexiletine in the treatment of painful diabetic neuropathy. The mexiletine study group. Diabetes Care 1997;20:1594-7. [CrossRef]

40. Tesfaye S, Selvarajah D. Advances in the epidemiology, pathogenesis and management of diabetic peripheral neuropathy. Diabetes-Metab Res 2012;28:8-14. [CrossRef] 